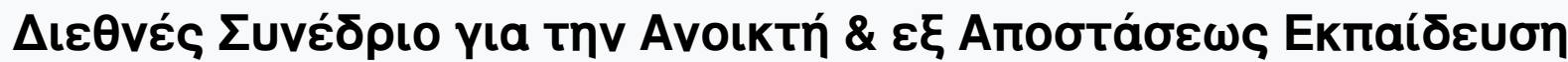

Tón. 5, Ap. 1A (2009)

Open and Distance Education for Global Collaboration \& Educational Development

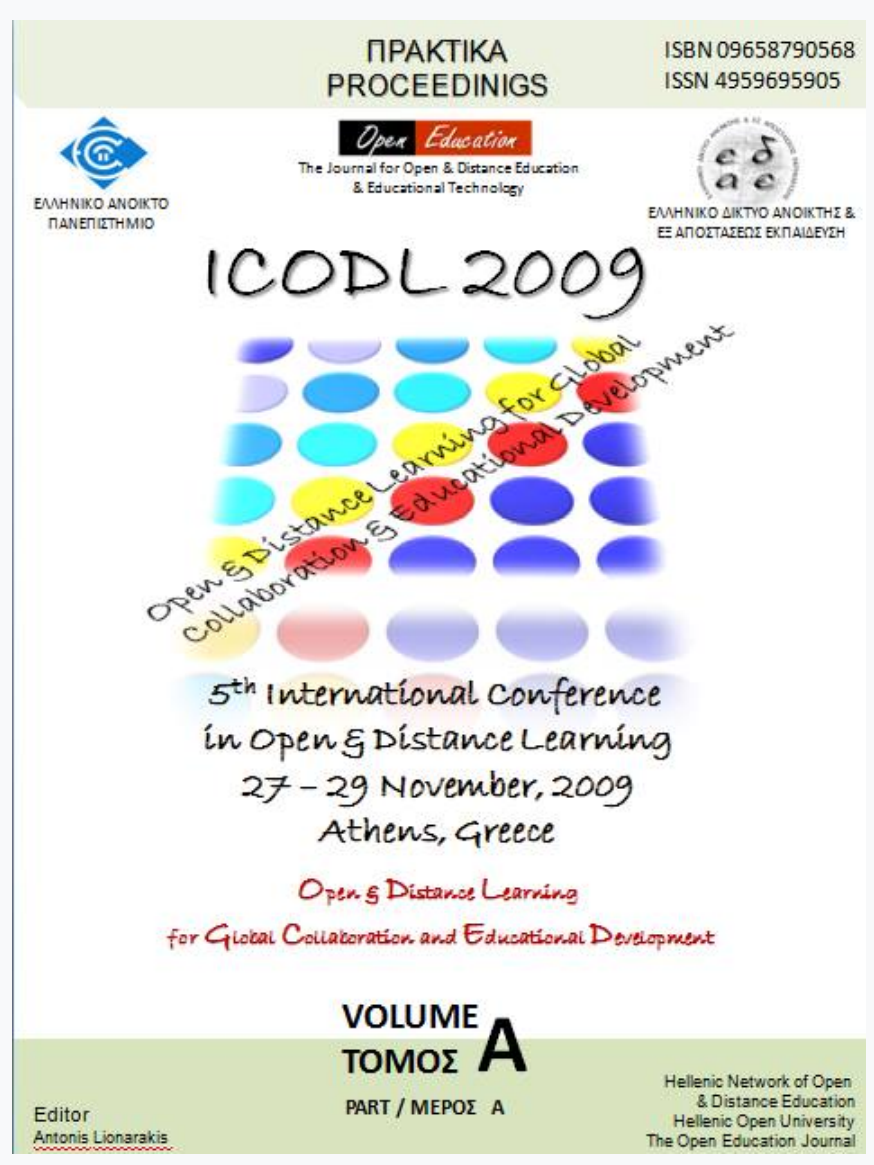

Cat got your Tongue: Analysis of student engagement on public and private online forums

Crystal MACHADO, Jennifer Elizabeth ROGERS

doi: $10.12681 /$ icodl. 483 
$5^{\text {th }}$ International Conference in Open \& Distance Learning - November 2009, Athens, Greece - PROCEEDINGS

\title{
Cat got your Tongue: Analysis of student engagement on public and private online
} forums.

\section{Crystal MACHADO}

Indiana University of Pennsylvania, Assistant

Professor,

cmachado@iup.edu

\author{
Jennifer Elizabeth ROGERS
}

\begin{abstract}
Educators in Higher Education must examine how innovative web-based technology can be used to facilitate the learning outcomes of the courses they teach. "Cat got your Tongue? An Analysis of Student Engagement on Public and Private Online Forums" reports on a scholarship of teaching and learning (SoTL) project that the author initiated in her classroom in spring 2008. The author describes the degree to which aspiring school leaders' engaged in discourse online on two popular and influential forums for online discourse, namely: the discussion board feature of Blackboard - a course management system - and weblogs. In addition, the author evaluates the degree to which study participants' discourse contained retrospective, anticipatory and contemporaneous reflection. The author concludes with a description of the challenges faced and the steps that can be taken to harness the pedagogical benefits of discussion board and weblogs as tools to promote critical thinking and reflective practice.
\end{abstract}

\section{Rational and Significance of the Study}

The changing demands in higher educating in the United States coupled with a flurry of reports from the 1980s and 1990s called for fundamental changes to leadership preparation programs. This attempt to bridge the gap between theory and practice has contributed to closer analysis of curriculum and pedagogical practices. Attempts are being made to engage students in field-based learning experiences that allow for skill development and the integration of theory, practice and research. Leadership preparation programs are requiring students to maintain portfolios and write reflections that document their mastery of standards. Over the last couple decades faculty have been experimenting with innovative web-based tools like discussion board (Garrison and Archer, 2001; Meyer, 2003) and weblogs (Farmer and Yu, 2007, Huffaker, 2007) which offer new opportunities to encourage dialogue, critical engagement, and reflective practice. This paper contributes to these discussions by detailing the rational for this single subject qualitative research study, the design and findings. 


\section{Theoretical Basis for the Study Benefits of Reflective Practice}

Our view of the world serves as a filter on our thinking. This, coupled by the fact that we often get accustomed to others directing what we do, and fall into routine ways of thinking, make it necessary for us to develop an internal mechanism that helps us to regulate and evaluate thought and action. Reflective thinking, which has been widely advocated by scholars (Dewey, 1933; Palmer, 1998; Schon, 1987), is a pedagogical practice that is becoming increasingly popular in school leadership preparation programs in the United States. Reflective thinking makes it possible for us to engage in self-talk (Costa and Kallick, 2000) hear our inner voice (Canning, 1991) and see things from multiple perspectives (York-Barr, Sommers, Ghere, Montie, 2006). It is believed that providing aspiring school leaders with an opportunity to sort, assimilate, analyze and evaluate knowledge will result in higher levels of metacognition (Hanna and Ottens, 1995), deeper understanding and integration of knowledge and experiences (Butler, 1996, William and Wessel, 2004), self-awareness, inner leadership, and opportunities for continued professional growth (Argryis and Schon, 1992; Pavlovich, 2007; York-Barret et.al, 2006). If done properly, it should contribute to social equity and the establishment of a just and humane society (Van Manen, 1977; Zeichmer, 1993).

\section{Types of Reflection}

Numerous scholars have contributed to conversation about the different ways of reflecting. The most popular approach and one that forms the theoretical foundation of this study is the typology advocated by Schon (1992) which includes reflection-in-action, a process of observing our thinking and action as they are occurring, in order to make adjustments in the moment, and reflection-on-action a process of learning from past experience in order to affect future action. Killion and Todnem (1991) expanded on this and added reflection-for-action or reflection-to-action. This type of reflection requires practitioners to envision the effect of interventions or actions on groups of students or colleagues, the learning environment, and/or the school as a community.

\section{Tools to Promote Critical Thinking and Reflective Practice}

Bohm (1989) describes dialogue as a stream of meaning that flows among us, through us, and between us. This definition can encompass the inner exploration of assumptions and viewpoints that takes place within us. While we all have the potential to engage in this inner dialogue, we need to teach ourselves how to do so meaningfully (York-Barr et. al, 2006). Creating a supportive culture and space where students had an opportunity to reflect and learn was the intent of this project. Numerous authors have discussed how dialogue can be used to promote critical thinking and reflective practice (Bohm, 1989, Isaacs, 1999). Two influential avenues for online discourse that provide 
opportunity for dialogue beyond the classroom are discussion boards and weblogs (blogs).

Innovative web-based technology like discussion boards, a tool embedded in course management systems like Blackboard and ANGEL, facilitate computer mediated communication between students and instructors outside of the classroom (Freuhoff, 2008; Wang and Hsua, 2008). Discussion boards became popular because they afforded students the opportunity to learn on their own and teach others, write intensively, engage in interactive discussions, and become part of an intimate community (Kassop, 2003).

Blogs are websites created by individual authors who post ideas that accumulate in reverse chronological order on the same page. Students can personalize their own blogs, and control access to their site. Blogs have been gaining popularity at a phenomenal rate and have the potential to be used to enhance teaching and learning (William and Jacobs, 2004). In addition to facilitating self-publication blogs have the capacity to promote personal affirmation, empowerment, interpersonal sociability and collective bonding (Kaye, 2006; Poling, 2005). Both O'Donnel (2006) and Farmer (2006) maintain that blogging aids in the development of higher order learning skills, active learner centered pedagogy, authentic learning, associative thinking, and the creation of interactive learning communities.

\section{Purpose of the Study}

The concept of 'prosumers' recognizes that students can move beyond the learning subject content and/or techniques of critical analysis and reach the level of applying such knowledge and integrating it as part of their intellectual growth within their daily lives Reflective practice and critical thinking, which lie at the heart of this concept, became the key learning objectives of a Theories of Instruction course in spring 2007. This single subject qualitative research study was designed to explore the potential of discussion board and weblogs for higher level thinking, in particular, reflections involving retrospective, anticipatory and contemporaneous thought. The following five questions guided the study:

1. How frequently do students engage in dialogue with other students on discussion board during the course of a semester?

2. How frequently do students post their thoughts on their personal blogs during the course of a semester?

3. Is there a difference in the degree to which students engage in retrospective, anticipatory and contemporaneous reflection in the public forum (discussion board) and the private forum (personal blog)? Which forum lends itself to a higher level of thought and action?

4. What were some of the pedagogical benefits of using discussion board and weblogs to promote critical thinking and reflective practice?

5. What are some of challenges faced, and how can they be addressed in subsequent studies?

Context of the Study 
Participants. A total of twenty graduate students, enrolled at three different satellite campuses, who signed up for a Masters level Theories of Instruction course in spring 2008 participated in this study. The class comprised of six males, and fourteen females; five were African American, and the rest were Caucasian. For a period of fourteen weeks $\mathrm{I}$, as instructor of the course, had face to face interaction with fourteen students at one campus, and interacted with the students at the two other campuses through the Compressed Video Network (CVN), better known as interactive television. In addition to the weekly three hour CVN session each student was required to use the discussion board feature of Blackboard - a course management system- and maintain a personal blog.

Data Collection Procedures. Data were generated from the following sources: (1) a preliminary survey which elicited demographic data and documented their experience with reflective writing and the value they placed on it, (2) their engagement of discussion board, (3) their personal blogs and, (4) their individual action research reports. During the first phase participants used the public forum (discussion board) to respond to the stimulus (literature, case studies, audio clips, you-tube clips, video, etc.) and bounce ideas off each other. They used the private forum (blogs) to introspect, confront personal beliefs and biases, process the application of course content to their own context, and generate workable solutions. During the second phase participants continued to respond to the stimulus material in the public and private forum. Additionally, they were encouraged to use their blogs to capture their reflective thoughts as they developed, implemented and reported on an action research study that the conducted in their classrooms.

Crème (2005) maintains that grades signal the importance of what is being taught; and Varner and Peck (2003) advocate the use of grades as a reward for energy invested in the task. As such, ten of the fourteen discussion board threads were graded in increments of five points. Students could secure a total of 50 points. Blogs were graded thrice during the semester, in increments of 20 points; students could score a total of 60 points. The point value for both discussion board and weblog posts amounted to 25 percent of the overall grade.

Data Analysis. Qualrus, a qualitative research software was used to analyze the data. Based on the frequency of their posts over the course of fourteen weeks students were categorized into the following four groups: Advanced, Above Average, Average, and Below Average. Each individual post was then analyzed to identify the number of times the student made a retrospective, contemporaneous, and anticipatory comment. SPSS was used to quantify the qualitative data.

Discussion and Findings

\section{Frequency of Student Engagement on Discussion Board and Blogs}

Students were instructed to post approximately 3 to 4 times a week on discussion board, during the fourteen week semester. Over the course of the semester students posted a total of 1373 posts. After statistically eliminating the outliers, which included a student who posted as little as 20 posts, and another who posted 180 times, the students were grouped into the four categories. Table 1 shows that the majority of students posted between 2 to 3 posts each week. Half the class exceeded expectation, the students in the Above Average category posted between 4 and 6 times a week and those in the Advanced category posted between 8 to 13 times each week. 
Table 1

Discussion Board Engagement over a Period of 14 Weeks: Frequency of Posts

\begin{tabular}{lll}
\hline Engagement Level & Number of Posts & Number of Students \\
\hline Advanced & $101-184$ & 3 \\
Above Average & $61-100$ & 7 \\
Average & $30-60$ & 9 \\
Below Average & $1-30$ & 1 \\
\hline
\end{tabular}

Students were told that their personal blogs would be graded thrice during the course of the semester. They were given the freedom to post as little or as often as possible. Over the course of the 14 weeks students posted a total of 109 posts. In-spite of repeated reminders some students failed to post consistently on their blogs. Table 2 shows that the number of posts ranged from 2 to 7 , with an average of 5 posts per student. Thirteen students posted between 6 and 7 posts.

Table 2

Blog Engagement over a Period of 14 Weeks: Frequency of Posts

\begin{tabular}{lll}
\hline Engagement Level & Number of Posts & Number of Students \\
\hline Above Average & $6-7$ & 13 \\
Average & $3-5$ & 7 \\
\hline
\end{tabular}

Judging from the frequency of the posts, it is evident that students were drawn to post more often on discussion board, than they were on their personal blogs. Additionally, there appears to be a greater variability in levels of engagement on discussion board, than blogs; students were placed in two additional categories on discussion board: Advance and Below Average.

\section{Quality of Student Engagement on Discussion Board and Blogs}

The stimulus material used in class was used to spark off retrospective, contemporaneous, and anticipatory refection. Students' posts were analyzed to examine the degree to which they engaged in each of the forms of reflection, each comment within a post was coded individually. Given the nature of the content that was covered only ten of the fourteen weeks lent themselves to detailed case and cross-case analysis. Apart from a few outliers; there was very little evidence of retrospective and anticipatory comments on both discussion boards and blogs (see Table 3 and Table 4). Students engaged in contemporaneous reflection to a higher degree (709 comments) than they did with either retrospective ( 275 comments) or anticipatory reflection (87 comments) on discussion board (see Table 3). A similar trend was observed on blogs, students engaged in contemporaneous reflections ( 252 comment) to a higher degree than either a retrospective (70 comments) or anticipatory (77 comments) reflection. One plausible reason for this 
could be that preparation programs emphasize more on contemporaneous and retrospective reflection, rather than anticipatory reflection. It would be interesting to see if there is a relationship between the number of anticipatory comments and locus of control.

Table 3

Discussion Board Engagement: Frequency and Quality

\begin{tabular}{llll}
\hline Engagement Level & Retrospective & Contemporaneous & Anticipatory \\
\hline $\begin{array}{l}\text { Advanced }(\mathrm{n}=3) \\
\text { Above Average (n }\end{array}$ & 92 & 222 & 23 \\
$=7$ ) & & 272 & 37 \\
$\begin{array}{l}\text { Average }(\mathrm{n}=9) \\
\text { Below Average }\end{array}$ & 72 & & \\
$=1$ & & 207 & 26 \\
Total & & 8 & 1 \\
\hline
\end{tabular}

Table 4

Blog Engagement: Frequency and Quality

\begin{tabular}{llll}
\hline Engagement Level & Retrospective & Contemporaneous & Anticipatory \\
\hline $\begin{array}{l}\text { Above Average }(\mathrm{n}= \\
\begin{array}{l}12) \\
\text { Average }(\mathrm{n}=6)\end{array}\end{array}$ & 24 & 170 & 40 \\
\hline
\end{tabular}

Group differences were observed in the number of retrospective and contemporaneous comments made by students on discussion board, when compared across engagement level. Students who were placed in the Advanced category, posted many more retrospective and contemporaneous comments $(M=30.66,74.0$ respectively) than students placed in the Above Average $(\mathrm{M}=15.29,38.86$ respectively), Average $(\mathrm{M}=$ 8.0, 23.8, respectively) and Below Average category $(\mathrm{M}=4.0,8.0$, respectively). Conversely independent samples $t$ test confirmed the number of anticipatory, contemporaneous and anticipatory comments made on blogs were not statistically different when compared across engagement level.

Motivation to Post

Pedagogical Benefits and Instructional Challenges

A comparison of student engagement, based on number of posts, across the two the two forums is shown in Table 3.

Table 3

Level of Participation across Public and Private Forums

\begin{tabular}{llll}
\hline Engagement Levels & Discussion Board & Weblogs & Discussion Board \& Blogs \\
\hline Advanced & $5,8,19$ & - & - \\
Above Average & $1,3,7,15,16$ & $5,6,8,9$, & $2,11,14$ \\
\hline & SECTION A: theoretical papers, original research and scientific articles & 45
\end{tabular}


$12,17,18$

19,20

Average

$6,9,12,14,17,20$

$1,3,7,15$,

16
$4,10,13$

Below Average

18

*The numbers in this Table represent individual student.

As evident from Table 3, the majority of students' level of engagement varied across the two forums; students who posted less frequently on discussion board posted more often on their personal blogs, and vice versa. The three students, who were ranked as 'Advanced' for their engagement on discussion board, were ranked as 'Above Average' for their blog engagement (students 5, 6 and 19). Similarly, students who were ranked as 'Above Average' for their participation on discussion board were ranked 'Average' for their engagement on their blogs (students 1, 3, 7, 15 and 16). Conversely, six students who were classified as 'Average' on discussion board (students 6, 9, 12, 14, 17 and 20) and one that was classified as 'Below Average' (student 18) showed 'above average' performance on their blogs. Only six of the twenty students contributed consistently on both their blogs and on discussion board; three of which were classified as 'Above Average' (students 2, 11, and 14) and three were classified as 'Average' (students 4,10 , and 13). Given the variability in motivation to post on the two forums I will, in future, use either both forums simultaneously, or offer students the option of engaging in a forum of their choice.

Not a single student moved beyond the minimum requirement of blog posts, in terms of frequency. Some of the factors that could account for the limited number of posts are listed below:

Expectations. Comments in class like "I do not know when to write and how much to write!" and "What should be the difference between our blog posts and discussion board posts?" reveals that students found it hard to distinguish between the expectations for each forum. This could have contributed to the limited number of blog posts.

Past Experience. Although the every student in the class had written reflections for previous courses, this course required a higher level of critical thinking and reflection. The comment below, illustrates that students are not always accustomed to capturing their thoughts in writing:

I learned that one of my weaknesses is in the recording of thoughts and ideas. I have a tendency to keep it all in my head. This has been realized through my difficulty in keeping up with appropriate blog entries, which was to serve as my record keeping. Some of the ideas that I had were lost because of my lack of efficient and continuous record keeping. Therefore, I know that next time I be more diligent in this aspect of the action research process. I have several future projects that I want to conduct next year through this method, and I am excited to see the results. (student 2) 
External Locus of Control. The majority of students seemed to have an external locus of control. High levels of preoccupation with the statewide testing, and the impact that the results could have on their careers was evident. One student said:

...my thesis twisted and turned a great deal over the last month. I had a few factors that slowed down this process for me....Testing...testing...testing...the last three weeks...the students have tested here... there ...almost everywhere...that's a whole other research subject! (Student 1)

Other comments, in a similar vein, made me wonder if the educational system is doing enough to empower students.

Incentives. The tone of the content and frequency of their posts in the public forum, discussion boards, reflected high levels of motivation. Grades, coupled with the element of social interaction, appear to have been a powerful motivator with discussion board. At times it was hard to determine if students commented on others' posts to get credit, as is often the case in a pseudo community (Grossman, Wineburg and Woolworth, 2001) or because they had bought into the concept of a learning community. Grades were a powerful motivator on blogs as well; there was an increase in the number of posts prior to the first of the month, when I graded their blogs. However, grades, in the absence of social interaction, were not powerful enough to get them to post beyond the minimum requirement of seven blog posts. Giving students an opportunity to share their blogs with the public might lead to the reflective benefits that accrue when one's writing are read and critiqued by a larger audience.

Students obviously need more support during the early stages of blogging. To help make the exercise more user-friendly and critically transformative, in future, I will expose them to typical blog posts, get them to critically analyze the content of personal and professional blogs, and discuss the pedagogical and professional benefits of using blogs as reflective writing tools. Together we will generate descriptive detailed guidelines that they can use when they blog. I will then initiate them into the use of 'low threat' 'getting to know you' type of ....blog memes (such as list of favorite TV shows, video games, movies etc.), encourage students to generate their own version of blog memes, and gradually initiate them into reflecting on critical issues and practices in their classrooms and schools.

Organization of Posts

While the threaded nature of discussion board, afforded students an opportunity to contribute to multiple discussions, and interact with a wide range of students, it did result in writing that was fractured. At times, students had difficulty monitoring their own thoughts, and making connections across topics. Their posts on blogs, although few and far between were more analytical and reflective, and tied closely classroom action. This could be attributed to the fact that they were contained in a single self-controlled space, Students have the opportunity to monitor their own thoughts over time and maintain connections across topics, uninterrupted by the cacophony of others' voices resounding silently in the background.

Value Placed on Each of the Forums

The tone and content of students' blogs reveal that value the placed on the exercise. Some students, including those who fell in the 'Above Average' category, did not 
recognize that the blog was intended to provide them with an opportunity to introspect, explore, integrate, and arrive at resolution.

Finally....my very last post to this whole blog thing.....which I'm not terribly fond about! I find that it's very difficult to sit and post to something when information could have just as easily been shared face to face. That's something that I feel is wrong with the youth of today....too much electronic communication.....I believe that there is nothing like a "good ole face to face" meeting to do a heart good. Not that I'm any way, type, shape, or form of a conservative...but I do feel that face to face communication and human interaction is the best form of communication. Now that I got that off my chest...(student 20)

The majority of the students succeeded in breaking away from the usual passive voice and densely referenced text familiar in academic writing. They began to take more risk and find their personal voice. Over the course of the semester the tone of the posts changed. Their comments reflected articulation of issues and problems, exploration, integration, and resolution:

This entire process has really encouraged me to reflect on my teaching and my classroom practices. Am I doing what is best for my students individually? Collectively? Am I providing the very best method of instruction for them? The project has encouraged me to keep pushing for the horizontal and grade level meetings that my principal has promised. (student

Some students started to use their blogs to relieve stress and to celebrate:

I am up at 3:26 in the morning stressed... I am up at 3:26 in the morning stressed. It really feels comforting to be able to write in all down and express my feelings. I think I will go to bed. (student 8)

This last phase worked. My students outscored the other 2 first grade classes with a $93 \%$. I was so happy that when the math coach brought me the scores I yelled right there in the hallway! The students were excited as well. One of my students that was absent begged me if she could make it up, which by this time, was too late. She wanted to be a part of this celebration! (student 12)

Comments by some students, towards the latter part of the semester, confirmed that they

had begun to see the value of their blogs:

I have to say that when I was writing my paper, this blog became important to reflect upon. I was able to see how I was progressing or regressing. I have been writing in a notebook like my students as part of my blog and that have really helped me. I find myself writing more each day and week about class. I write down the good and bad event of the day. I enjoyed looking at it. (student 8)

I'm really excited about changing BHS and most of our students' lives for the better!!!! I've really enjoyed writing these blogs and hope to continue to do so after this class is over. I guess I'll have to "branch out" and try new things by blogging when you aren't there to make me!!!! (student 5)

Use of the Three Different Types of Reflection 
On both discussion board and blogs, students engaged in reflection-in-action (contemporaneous) to a higher degree than reflection-on-action (retrospective) or reflection-for-action (anticipatory). While it is essential for education practitioners to observe their thinking and actions as they are occurring, it is equally important they learn from past experience and envision to effect of actions and interventions on students, colleagues and the learning environment. To get students to engage more actively in all three types of reflection, especially retrospective and anticipatory reflections I intend to include more explicit guidelines about what constitutes 'self-reflexivity' so that students learning how to reflect on their daily activities in a concise and analytical manner. In addition, I will provide students with an opportunity to complete summative feedback questionnaire at the end of the session.

Final Thoughts

If we are to help our students in higher education to bridge the gap between theory and practice it is vital that we teach them how to engage in the messy process of reflection in, on, and for action which provide feedback that can lead to significant cultural change in schools. This study confirms that potential of innovative web-based technology and the need for further investigation of the pedagogical benefits of discussion boards and blogs. Consistent to the observations of Kassop (2003), my students demonstrated a willingness to write intensively, engage in interactive discussions, and become part of an intimate community. In addition, they strived to examine issues from multiple perspectives (York-Barr, et al., 2006). While the majority demonstrated high levels of engagement both in terms of quantity and quality, those that were inactive or less active demonstrated a need more scaffolding. Engagement on blogs, though less frequent, were content rich. Students engaged in self-talk (Costa and Kallick, 2000 ) that was action oriented; displayed personal affirmation and empowerment (Kaye, 2006); and the development of higher order skills and authentic learning (Farmer, 2006; O'Donnel, 2006). Students performed differently across the two forums, which suggest that student learning can be maximized if I match the forum with students' individual preference.

This study has helped me to identify a number of areas which merit further work. In subsequent studies I will experiment with approaches that with help me to: (1) find ways of increasing students ability to engage in reflection-on-action and reflection-for action; (2) find more desirable incentives for participation, ones that will move students from a pseudo-community that is driven by grades to a learning community that is intrinsically motivated; (3) find the right balance between allowing students to self regulate, and facilitating student inactivity; and finally (4) provide students with a space that is private enough for them to find their voice, and public enough to benefit from social critique.

\section{References}

Argryis, C. \& Schon, D. (1992). Theory in practice: Increasing professional effectiveness. San Francisco: Jossey- Bass (originally published in 1974).

Bohm, D. (1989). On dialogue. Ojai, CA.: David Bohm Seminars. 
Butler, J. (1996). Professional development: Practice as text, reflection as process, and self as locus. Australian Journal of Education, 40(3), 265-283.

Canning, C. (1991). What teachers say bout reflection? Educational Leadership 48 (6), 1821.

Costa, A.L., \& Kallick, B. (2000). Getting into the habit of reflection. Educational Leadership, 57(7), 60-62.

Crème, P. (2005). Should student learning journals be assessed? Assessment and Evaluation in Higher Education, 30(3), 287-296.

Dewey, J. (1933). How we think: A restatement of the relation of reflective thinking to the educative process. New York: D.C. Heath \& Co.

Farmer, J., \& Yu, R. (2007). Blogging to basics: How blogs are bringing online education back from the brink. In A. Bruns \& Jacobs (Eds.), Uses of blogs (pp.91-103) New York: Peter Lang.

Freidhoff, J.R. (2008, Summer). Reflecting on the affordance and constraints of technologies and their impact on pedagogical goals. Journal of Computing in Teacher Education, 24(4), 117- 122.

Garrison, D. R., Anderson, T., and Archer, W. (2001). Critical Thinking, Cognitive Presence, and Computer Conferencing in Distance Education. The American Journal of Distance Education, 15(1), 7-23, 2001.

Grossman, P., Wineburg, S., \& Woolworth, S. (2001). Towards a theory of teaching community. Teachers College Record, 103(6), 942-1012.

Hanna F.J. \& Ottens, A.J. (1995). The role of wisdom in psychotherapy. Journal of Psychotherapy Integration, 5, 1995-210.

Huffaker, D. (2005). The educated blogger: Using weblogs to promote literacy in the classroom. AACE Journal, 13(2), 91-98.Kaye, B.K. (2006).

Kassop, M. (2003, May/June). Ten ways online education matches, or surparses, face-to-face learning. The Technology Source. Retrieved April 20, 2009 from $\mathrm{http}: / /$ distance.wsu.edu/facultyresources/savedfromweb/10ways.htm

Kaye, B.K. (2007 ). Blog use motivations. An exploratory study, pp.27-148. In M. Tremayne (Ed.), Blogging, citizenship, and the future of media. New York: Routledge.

Killion, J. \& Todnem, G. (1991). A process of personal theory building. Educational Leadership, 48(6), 14-17.

Meyer, K. (2003). Face-to-face versus threaded discussions: The role of time and higherorder thinking. The Journal of Asynchronous Learning Networks, 7(3), 55-65.

O’Donnel, M. (2006). Blogging as pedagogical practice: Artifact and ecology. Asia Pacific Media Educator, (17), 5-19.

Palmer, P.J. (1998). The courage to teach. San Franciso, CA: Jossey-Bass.

Pavlovich, K. (2007). The development of reflective practice through student journals. Higher Education Research and Development, 26(3), 281-295.

Poling, C. (2005). Blog on: building communication and collaboration among staff and students. Learning and Leading with Technology, 32(6), 12-15.

Schon, D. (1987). Educating the reflective practitioner: Towards a new design for teaching and learning in the professions. San Francisco: Jossey-Bass, Inc.

Van Manen, V. (1977). Linking ways of knowing with ways of being practical. Curriculum Inquiry, 6(3), 205-228. 
Varner, D., and Peck, S. (2003). Learning from learning journals: The benefits and challenges of using learning journal assessments. Journal of Management Education, 27(1), 52-77.

Wang, S., \& Hsua, H. (2008, May/June). Reflections on using blogs to expand in-class discussions. Tech Trends, 52(3), 81-85.

William, R., and Wessel, J. (2004). Reflective journal writing to obtain student feedback about the learning during the study of chronic musculoskeletal conditions. Journal of Applied Health, 33(1), 17-23.

Williams, J.B., \& Jacobs, J. (2004). Exploring the use of blogs as learning spaces in the higher education sector. Australasian Journal of Educational Technology, 20(2), 232247.

York-Barr, J., Sommers, W.A., Ghere, G.S, Montie, J. (2006). Reflective practice to improve school: An action guide for educators. CA: Corwin Press.

Zeichmer, K. M. (1993). Connecting genuine teacher development to the struggle for social justice. Journal of Education for Teaching, 19(1), 5-20. 